\title{
Prevalence of juvenile idiopathic arthritis in schoolchildren from the city of São Paulo, the largest city in Latin America
}

\author{
Vânia Schinzel, Simone Guerra Lopes da Silva, Maria Teresa Terreri and Claudio Arnaldo Len * (D)
}

\begin{abstract}
Background: Juvenile idiopathic arthritis (JIA) is a chronic inflammatory disease that affects children and adolescents. Its prevalence varies greatly from one study to another according to the population and methodology. Some tools may be helpful in screening for suspected cases. The aim of this study is determine the prevalence of JIA in children and adolescent students in the city of São Paulo, Brazil.

Methods: This cross-sectional study was conducted from March 2016 to November 2017. It was based on a populational study envolving school children and adolescents from São Paulo, the largest city of Brazil. We randomly selected students under 16 years old from private schools with more than 1000 students who were evaluated through a specific questionnaire for screening suspected cases of chronic arthropathy (Early Diagnosis of Chronic Arthritis - 12 items - EDA-12) and subsequent anamnesis and rheumatologic physical examination for diagnostic confirmation.

Results: We contacted all 79 schools in the universe, of which $12(15,18 \%)$ agreed to participate in the study. A total of 21,119 questionnaires were handed out to the parents. We obtained a response of 5,710 (27\%). In 108 cases the EDA-12 score was considered positive $(\geq 5)$. We examined all these 108 "suspicious" children. In 10 cases, the rheumatologic evaluation confirmed the diagnosis of arthritis, since the subjects presented a history and physical examination compatible with JIA. The prevalence of JIA in children and adolescents was $0.196 \%(95 \% \mathrm{Cl}=0.104-$ $0.371 \%)$.

Conclusion: In this first Brazilian population study to evaluate the prevalence of JIA, we observed that the disease is relatively prevalent in our country (196/ 100.000 children), which is similar to that observed in other studies involving children from urban centers.
\end{abstract}

Keywords: Juvenile idiopathic arthritis, Arthritis, Prevalence, Questionnaires, Epidemiology, Pediatrics, Rheumatology

\section{Background}

Juvenile idiopathic arthritis (JIA) is the most prevalent chronic rheumatic disease in childhood and adolescence [1]. This disease is characterized by the presence of chronic inflammatory arthropathy and extra-articular manifestations [2]. A delay in the beginning of specialized treatment can lead to progressive and destructive arthritis [3, 4]. Therefore, the early identification and

\footnotetext{
* Correspondence: claudiolen@gmail.com

Pediatric Rheumatology Unit, Department of Pediatrics, Escola Paulista de Medicina, Universidade Federal de São Paulo (UNIFESP), Rua Borges Lagoa, 802 - Vila Clementino, São Paulo 04038-001, Brazil
}

treatment of children and adolescents with AIJ is a concern to all rheumatologists $[5,6]$.

Strategies to improve the referral of suspected always stand in the need of an adequate knowledge of the prevalence of the disease and a correct referral to the rheumatologist [7-9].

The prevalence of JIA varies among populations, possibly due to genetic and epigenetic aspects of the disease. In systematic cases review, there was a variation between 3.83 to 400 cases / 100,000 children [7]. However, there are no studies on JIA prevalence in many countries, including Brazil, one of the most populous countries in the world. The epidemiological knowledge of the disease

(C) The Author(s). 2019 Open Access This article is distributed under the terms of the Creative Commons Attribution 4.0 International License (http://creativecommons.org/licenses/by/4.0/), which permits unrestricted use, distribution, and 
is important to develop strategies for early diagnosis and for the referral of suspected cases, especially in the case of diseases that can lead to a functional disability, such as JIA and other rheumatic diseases.

In the last decades, several methodologies have been used to determine the prevalence of JIA. However there is no design standardization in this various international studies [10-18]. Different methods have been used to obtain the prevalence, including data collection through population and hospital databases, questionnaires or interviews with professionals in health centers or parents/caregivers and physical examinations in the sample as a whole. All of these methods have positive and negative aspects [19]. In 2005 we developed the questionnaire "Early diagnosis of arthropathy - 12 items" (EDA-12), which was validated, and whose purpose is to screen suspected cases of JIA [20]. EDA-12 has been and is being used in other countries as an early diagnostic tool [21].

Some authors have associated the application of questionnaires with physical examination of the joints [11-13, $16,17]$. However, in some studies, no specific validated questionnaires were used for the detection of suspected cases of chronic arthropathy. In addition, other criticisms refer to the restriction of the evaluated age range or the limitation of the group of participating children. At present, we use the Early Diagnosis of Arthritis 12 (EDA12) (questionnaire, which is a validated screening tool [20]. This questionnaire is composed of 12 simple questions addressed to parents/caregivers about various current and past signs and symptoms of JIA [20].

The questions include aspects of daily activities, such as walking, running, writing or drawing, the ability to play sports and aspects related to the general symptoms of chronic arthritis, such as the presence of joint pain or edema, deformities and even the presence of a fever or skin rash. The EDA-12 score ranges from 0 to 12, with each question given one point for a positive answer. A score greater than or equal to five points has a sensitivity of $89.58 \%$ and a specificity of $92.59 \%$ for the detection of patients with chronic arthropathy [20].

Therefore, to the best of our knowledge, this study is the first to determine the prevalence of JIA in a population of schoolchildren aged 1-16 years in a large Brazilian urban center based on the application of a valid questionnaire for detection of suspected cases of chronic arthropathy, followed by a standardized rheumatological physical examination in schoolchildren screened by the instrument.

\section{Casuistry and methods}

\section{Universe of research}

To determine the prevalence of JIA in the city of São Paulo, we applied the EDA-12 questionnaire to parents/ caregivers of children and adolescents from private schools, followed by a physical examination when necessary. We decided to do the study with students from private schools due to the lower interference of strikes in the school period and due to the regularity of the number of classes and students over the years. The study was also conducted at the largest colleges in the city, with more than 1000 students, due to the ease of access to a large number of students.

\section{Sample design}

Information on the type and size (number of students) of the schools was obtained from the School Census coordinated by the Instituto Nacional de Ensino e Pesquisas Escolares (National Institute of Education and School Research; INEP) and conducted in collaboration with the state and municipal education secretariats (with the participation of all public and private schools in the country). The Census available for the study was conducted in 2013.

According to this census, there are 3,639 private schools in the city of São Paulo. To guarantee better stability of the number of students and classes over time, we considered the universe of schools with more than 1 , 000 students and with all four levels of education (daycare, pre-school, primary and secondary education) [22].

A sample was performed by clusters (in this case, the schools), which were randomized using the SPSS statistical program. A total of 79 schools with the desired profile were selected, the first 30 of which were contacted first. In the case of refusal to participate, the following schools from the list were contacted.

\section{Sample size determination}

This study required an actual sample of 10,670 children to estimate the proportion of cases with JIA with a sampling error of $0.1 \%$ and a confidence level of $95 \%$ using an estimated JIA prevalence of 1:400 in children seeking medical consultation as the scaling variable.

The sample size calculations were performed using the Power Analysis and Sample Size System (PASS 2008) NCSS statistical software. Calculation of the sample size estimated above refers to the calculation of a simple random sample. Because the sample of this study was represented by clusters, the sample size was adjusted using the sample design effect (Deff - Design Effect) [23]. Assuming a Deff of 1.3 , the adjusted sample size is given by $1.3 \times 10,670=13,871$ questionnaires.

In addition, a loss (not returning the questionnaire) of $20 \%$ was assumed. Therefore, the final estimated sample size was $13,871 \times 1.2=16,646$ questionnaires.

\section{Inclusion criteria}

Children and adolescents between the ages of 1 and 16 years who attended selected private schools in the city of 
São Paulo from March 2016 to November 2017 and whose respondents answered the EDA-12 questionnaire were included.

\section{Exclusion criteria}

All students whose parents did not return the EDA-12 questionnaire and/or the completed consent form in a proper and timely manner were excluded.

\section{Contact with schools, questionnaire and consent form}

The selected schools were initially contacted by telephone. Subsequently, material was sent to the directors/ coordinators with the project accepted by the Research Ethics Committee, an explanatory letter to the parents, the EDA-12 questionnaire and the consent form. In some situations, one or more personal visits were made to explain the project and clarify doubts.

In case of acceptance of school participation, all parents/caregivers of students received a kit inviting them to participate in the study. The kit contained 1) an explanatory letter to the parents, 2) the EDA-12 questionnaire and 3) a consent form. As explained in the letter, the questionnaire and the consent form should be collected within a period of up to 15 days according to the distribution and collection schedules of the schools. Notably, the identity of each child was confidential, and only the initials, grade, age and sex were recorded.

The data were entered into Excel spreadsheets, and all students who scored equal to or greater than five points on the EDA-12 questionnaire were called for a physical examination.

\section{Rheumatological examination}

The anamnesis and rheumatological examination were performed by a specialist in pediatric rheumatology (V.S. and/or C.A.L.) in a quiet room in the school, always with the presence of a teacher and one of the parents or a caregiver according to the will of each family.

With respect to anamnesis, questions were asked about the duration of the sign or symptom (according to the responses to the EDA-12), and a suggestive history of arthritis in at least one joint for a minimum of 6 weeks was considered positive. During the physical examination, the following joints were examined through inspection, palpation and assessment of joint mobility: temporomandibular, sternum-clavicular, acromion-clavicular, cervical, thoracic, lumbar and sacroiliac spine, shoulders, elbows, wrists, metacarpophalangeal, proximal and distal interphalangeal, hips, knees, ankles, subtalar, intertarsal and metatarsophalangeal. For the diagnosis of arthritis, the presence of joint edema or the presence of two of the following findings were considered: pain at palpation, movement limitation, increase in local temperature or hyperemia.

\section{Feedback to parents/caregivers}

The parents were warned in cases that fulfilled the diagnostic criteria for JIA so that they would follow-up with the child's physician. In cases with a previous diagnosis of the disease, we advised maintaining the treatment normally.

\section{Ethical aspects}

This study was submitted to the local Ethics Committee. The principals/coordinators and the parents were informed about the study, and their participation was voluntary.

\section{Statistical analysis}

Prevalences were estimated considering the sample by clusters. To compare the sizes of the schools and the location regions of the participating and nonparticipating schools, Fisher's exact test was used due to the sample size. Evaluation of the variation factor of the number of students between 2013 and 2015-2017 was performed using Student's t-test for one sample. Student's t test assumes normality in the data, which was verified using the Kolmogorov-Smirnov test. For all statistical tests, a significance level of $5 \%$ was adopted. The statistical analyses were performed using SPSS 20.0.

The SPSS Complex-Samples module was used to calculate the prevalences.

\section{Results}

During the study, all 79 schools with more than 1,000 students and all school levels were contacted. Of these schools, 12 (15.2\%) agreed to participate voluntarily in the project in a timely manner (2016 and 2017 school years), and 67 did not agree to participate $(84.8 \%)$ for various reasons, such as divergent policy from the board of directors or the head of the school, lack of interest and privacy reasons. Even with this number of refusals, the sample of schools was considered adequate, since the sample included schools of various sizes $(p=0.682)$ and several geographic locations in the city $(p=0.129)$ (Table 1) In addition, no randomization of students was carried out and each participating school collaborated with a larger number of students, providing a representative sample.

Although there was a time difference between the School Census (2013) and the study period (2016/17), a steadiness in the number of students in the participating schools was observed (Student's t test for one sampleHo: factor $=1, p=0.793$ ).

In total, 21,119 questionnaires were distributed, and 5, $710(27 \%)$ were returned. Of these questionnaires, 108 (1.89\%) presented scores equal to or greater than five points. The parents of these students were called for anamnesis, and the students were called for a 
Table 1 Profile of the selected schools in the city of São Paulo in relation to the numbers of students and locations

\begin{tabular}{|c|c|c|c|c|c|c|c|}
\hline & \multicolumn{4}{|c|}{ School } & \multirow{2}{*}{\multicolumn{2}{|c|}{ Total }} & \multirow[t]{3}{*}{$p$} \\
\hline & \multicolumn{2}{|c|}{ Non- participants } & \multicolumn{2}{|c|}{ Participants } & & & \\
\hline & $\mathrm{N}$ & $\%$ & $\mathrm{~N}$ & $\%$ & N & $\%$ & \\
\hline Size Tertiles & 67 & $100.0 \%$ & 12 & $100.0 \%$ & 79 & $100.0 \%$ & 0.682 \\
\hline$\leq 1167$ students & 24 & $35.8 \%$ & 3 & $25.0 \%$ & 27 & $34.2 \%$ & \\
\hline 1168-1567 & 22 & $32.8 \%$ & 4 & $33.3 \%$ & 26 & $32.9 \%$ & \\
\hline $1568+$ & 21 & $31.3 \%$ & 5 & $41.7 \%$ & 26 & $32.9 \%$ & \\
\hline Region & 67 & $100.0 \%$ & 12 & $100.0 \%$ & 79 & $100.0 \%$ & 0.129 \\
\hline MSP East Zone 1 & 17 & $25.4 \%$ & 2 & $16.7 \%$ & 19 & $24.1 \%$ & \\
\hline MSP East Zone 2 & 7 & $10.4 \%$ & 1 & $8.3 \%$ & 8 & $10.1 \%$ & \\
\hline MSP South Zone 1 & 13 & $19.4 \%$ & 2 & $16.7 \%$ & 15 & $19.0 \%$ & \\
\hline MSP South Zone 2 & 5 & $7.5 \%$ & 1 & $8.3 \%$ & 6 & $7.6 \%$ & \\
\hline MSP West Zone & 7 & $10.4 \%$ & 6 & $50.0 \%$ & 13 & $16.5 \%$ & \\
\hline MSP North Zone 1 & 7 & $10.4 \%$ & 0 & $0.0 \%$ & 7 & $8.9 \%$ & \\
\hline MSP North Zone 2 & 5 & $7.5 \%$ & 0 & $0.0 \%$ & 5 & $6.3 \%$ & \\
\hline MSP Central Zone & 6 & $9.0 \%$ & 0 & $0.0 \%$ & 6 & $7.6 \%$ & \\
\hline
\end{tabular}

2013 Census [22]

$p$ Descriptive level of Fisher's exact test

MSP Municipality of São São Paulo

rheumatological examination at school. After the physical examination and anamnesis with the parents, ten children met the diagnostic criteria for JIA (Table 2). Of these children, five were girls and five were boys. The ages ranged from 4 to 13 years, and the numbers of joints varied from one to ten. Regarding the type of onset, seven had oligoarticular and three had polyarticular disease. All reported that they were already in follow-up with pediatric rheumatologists and ophthalmologists, although without uveitis.

Therefore, we estimated that JIA was present in $0.196 \%$ (95\% CI $=0.104-0.371 \%)$ of children aged 1 to 16 years in the participating schools (i.e., the estimated prevalence was 196 cases/100,000 children and adolescents) (Tables 2 and 3).

\section{Discussion}

Despite being considered the most common rheumatic disease in childhood and adolescence, the prevalence of JIA is unknown in many developing countries, including Brazil. In the present study, which was unpublished in our field, we observed an estimated prevalence of 196/100,000 school children from a large urban area. We selected a methodology used in other studies $[11-13,15,17]$ that combined the application of a screening questionnaire [20] to parents and caregivers with a subsequent rheumatological physical examination in suspected cases. The highlights of our study were the use of a validated instrument for screening cases of JIA and performance of a standardized physical examination of the joints by specialists in pediatric rheumatology.

Determining the prevalence of JIA is not a simple task. Several factors are limiting to the performance of epidemiological studies, including diagnostic difficulty, frequent changes in classification criteria and different forms of disease presentation [2]. In addition, the absence of a unified registration in many countries, populations or hospitals prevents more accurate collection of epidemiological data. However, over recent decades, several population studies have been conducted in different countries, with different methodologies depending on the structure of each locality [10-19]. The objective of most of these studies is to assist in planning the structure of health services for the care of suspected and diagnosed cases $[8,9]$. In a systematic review of the literature, Thierry et al. [7] reported that the incidence and prevalence of JIA greatly varied from one study to

Table 2 Estimation of the JIA prevalence in the city of São Paulo

\begin{tabular}{llll}
\hline & Estimate (\%) & SE (\%) & 95\% Confidence Interval (\%) \\
\hline$P(J \mid A=$ Present/Score $\geq 5)$ & 11.263 & 3.272 & $5.816-20.692$ \\
$P($ Score $\geq 5)$ & 1.758 & 0.312 & $1.188-2.594$ \\
$P(J \mid A$ present $)$ & 0.196 & 0.057 & $0.104-0.371$ \\
\hline
\end{tabular}


Table 3 - Prevalence, amplitude of the 95\% confidence interval expected and performed

\begin{tabular}{lll}
\hline & Expected & Performed \\
\hline Prevalence of JIA & $0.250 \%$ & $0.196 \%$ \\
Lower confidence interval 95\% & $0.150 \%$ & $0.104 \%$ \\
Upper limit of confidence interval 95\% & $0.350 \%$ & $0.371 \%$ \\
Sample & 13,871 & 5,709 \\
Confidence interval range of 95\% & $0.200 \%$ & $0.267 \%$ \\
Deff & 1.300 & 1.287 \\
\hline
\end{tabular}

another (1.6 to $23 / 100,000$ children and 3.8 to $400 / 100$, 000 , respectively) according to the methodology used.

Studies based on physical examination performed in different populations showed a prevalence ranging from 34.9 to $37 / 100,000$ children [16]. In cases of national or regional databases, the prevalence varied between 16 and 140/100,000 children [14, 17]. Studies based on medical records showed a prevalence between 3.43 and 148/100.000 children [10, 18, 20]. In our review, we found five studies based on the association of screening questionnaires and physical examinations of suspected cases, which was the methodology used in the present study. In these cases, the prevalence ranged from 48 to $400 / 100,000$ children [11-13, 16, 17]. As expected, our results were similar to these studies, since we observed a prevalence of $196 / 100,000$ children aged 1 to 16 years old.

According to Table 3, it can be noted that although only a little more than $41 \%$ of the sample was reached, the final deff was observed as expected. The amplitude of the confidence interval increased by 0.067 percentage points (absolute values) by moderately increasing the accuracy of the interval estimate. Thus, it can be considered that the results were acceptable despite the loss that occurred during the sample collection.

Generally, all prevalence survey methods have advantages and disadvantages. Studies based on active searches, such as ours, allow the detection of cases potentially without a previous diagnosis. However, refusal of voluntary participation may prevent individuals from being included in the database. Our data were within the expected range, since we observed an estimated prevalence of 196/100,000 schoolchildren between 1 and 16 years of age.

The city of São Paulo is the largest city in Brazil in terms of the number of inhabitants. At the last census in 2010 , the city had a population of $11,253,503$ inhabitants, of which 3,036,050 were under 19 years of age [24]. Because we do not have a quality record of major chronic diseases of childhood and adolescence or a health system with diagnostic data integration, which is a reality in most developed countries [10, 14, 18], we opted for a methodology used in other studies with a focus on an active search for the disease [11-13, 16, 17].

Among several epidemiological studies, we observed that the absence of quality databases compelled other authors to use a similar strategy, with an active search for cases in the pediatric population. Mielants et al. [11] distributed questionnaires to the parents of 2,990 students from a secondary school in Belgium to screen suspected cases and subsequently performed a physical examination of suspected cases, with an estimated prevalence of 167/100,000 students. Manners et al. [12] conducted a JIA prevalence study in children up to 12 years of age in Australia. After randomization of children from the city of Perth, a questionnaire was distributed in schools, and all randomized children were assessed in a physical examination, with a prevalence of 400 cases/100,000 students. Tayel et al. [13] evaluated the prevalence of JIA in a simple and randomized sample of school children and adolescents between 10 and 15 years of age in Alexandria using a simple questionnaire and physical examination of suspected cases, with an estimated prevalence of 330/100,000.

Azam et al. [15] performed randomization of children and adolescents below 16 years of age in chosen regions in Bangladesh; all responded to a COPCORD questionnaire, and suspected cases were evaluated by physical examination to confirm the diagnosis. A prevalence of $60.5 / 100,000$ was estimated. Abujam et al. [17] estimated the prevalence of JIA in school children and adolescents from 6 to 17 years of age in northeastern India to be 48/ 100,000 based on the distribution of questionnaires and physical examinations of suspected cases. That study was closest to ours in terms of methodology, since its questionnaire was based on the EDA-12, which is a valid questionnaire. Standardization of the screening questionnaire used allows the data to be more comparable regardless of the study population.

In a study with a smaller city close to the size of the city of São Paulo (Embu das Artes), Yamashita et al. [16] observed a prevalence of 34/100,000 children by rheumatological physical examination of schoolchildren aged 6 to 12 years, all from public schools. However, this study did not evaluate children aged 5 years old or younger.

Case-finding studies have advantages and disadvantages compared to studies of database records. Among the disadvantages, we highlight the loss of cases at the time of the study and the difficulty in determining the incidence once the population is evaluated in a cross-sectional manner. As advantages, we cite the possibility of diagnosing new cases not recorded in databases (because the correct diagnosis was not made) and the closest contact with the population, including families, teachers and school principals, who receive some type of 
education about JIA, which usually is unknown to most of the population.

The EDA-12 includes questions about current and past signs and symptoms of JIA as a physical limitation for carrying out daily activities, such as walking, running, writing or drawing, as well as aspects related to the general symptoms of chronic arthritis, such as the presence of pain or joint edema and deformities [20]. This questionnaire also contemplates signs and symptoms of systemic JIA, such as a fever or skin rash [20]. Its sensitivity for the detection of suspected cases of chronic arthropathy is $89.58 \%$, and its specificity is 92.59\% [20]. Notably, the diagnosis of JIA is clinical and is possible only after careful anamnesis and a physical examination based on the ILAR criteria [2].

The reliability of using questionnaires for the identification of suspected cases depends on several factors. Data collection implies voluntary participation of the caregivers and adequate filling out of the instrument [24-26], either physically (printed paper) or digitally. Cultural habits, receiving spam and fear of theft of personal data result in a return of questionnaires via the internet of approximately 25\% [24-26]. In our study, we used printed questionnaires sent to parents via the school calendar or letter placed in the backpack, and the return rate was $27 \%$. We believe that this relatively low percentage was due to several factors, such as disinterest of parents/caregivers, privacy problems, forgetting and simple loss of the material. In addition, the refusal of schools to participate was high $(84.8 \%)$. In other carried out in developing countries the number of losses was also high. Abujam et al., in Bangladesh, used the same questionnaire and obtained only $10 \%$ of responses. [17]. Despite these issues, the data from our study were sufficient to reach our objectives.

One limitation of our study is the generalization of the data to other regions of the country, especially those that are less developed. The tuition at schools in the city of São Paulo, including the primary and secondary levels, is relatively high, which is not observed in a significant proportion of cities in Brazil, a country with continental dimensions. School dropouts are among the lowest, especially among high school students. In addition, we conducted our study in private schools, where the permanence of students over the years is higher than in public schools [24]. However, socioeconomic factors have no influence on the development of the disease (a fact observed in a series of infectious diseases), which can reduce the impact of this aspect on the epidemiological data for JIA.

Another limitation of our study was the low adherence of schools due to concerns about interference with school routine and the exposure of children. Throughout the collection of data we had many meetings with the principals of the schools, but a great part did not authorize the inclusion of its scholar. However we enrolled a number of participating individuals that allowed a statistical study of quality.

\section{Conclusion}

In the present study, we observed an estimated prevalence of 1.96 to 1000 schoolchildren from 1 to 16 years old in the city of São Paulo. This prevalence is within the range observed in similar studies conducted in other countries. In addition, the EDA-12 items questionnaire proved to be a useful tool in screening suspected cases of chronic arthropathy.

Abbreviations

EDA-12: Early Diagnosis of Chronic Arthritis - 12 items; INEP: National Institute of Education and School Research; JIA: Juvenile idiopathic arthritis

\section{Acknowledgements}

Not applicable.

\section{Authors' contributions}

VS: bibliographic review, data collection, introduction, methods, results, discussion. SGLS: bibliographic review, data collection, introduction, methods, results, discussion. MTRAT: discussion. CAL: data collection, introduction, methods, results, discussion. All authors read and approved the final manuscript

\section{Funding}

This study received a institutional support from Abbvie.

\section{Availability of data and materials}

The datasets used and/or analysed during the current study are available from the corresponding author on reasonable request.

\section{Ethics approval and consent to participate}

This study was submitted to the local Ethics Committee of Universidade Federal de São Paulo, number:1.402.940. The principals/coordinators and the parents were informed about the study, and their participation was voluntary.

Consent for publication

Not applicable.

\section{Competing interests}

The authors declare that they have no competing interests.

Received: 17 February 2019 Accepted: 12 July 2019

Published online: 25 July 2019

\section{References}

1. Olson JC. Juvenile idiopathic arthritis: an update. WMJ. 2003;102(7):45-50.

2. Petty RE, Southwood TR, Manners P, Baum J, Glass DN, Goldenberg J, et al. International league of associations for rheumatology classification of juvenile idiopathic arthritis: second revision, Edmonton, 2001. J Rheumatol. 2004:31(2):390-2.

3. Gueddari S, Amine B, Rostom S, Badri D, Mawani N, Ezzahri M, et al. Physical activity, functional ability, and disease activity in children and adolescents with juvenile idiopathic arthritis. ClinRheumatol. 2014:33(9):1289-94.

4. Glerup M, Herlin T, Twilt M. Clinical outcome and long-term remission in IIA. CurrRheumatol Rep. 2017:19(12):75.

5. McErlane F, Foster HE, Carrasco R, Baildam EM, Chieng SE, Davidson JE, et al. Trends in pediatric rheumatology referral times and disease activity indices over a ten-year period among children and young people with juvenile idiopathic arthritis: results from the childhood arthritis prospective study. Rheumatology (Oxford). 2016;55(7):1225-34. 
6. Len CA, Liphaus B, Machado CS, Silva CAA, Okuda E, Campos LMA, et al. Artrite reumatóide juvenil: atraso no diagnóstico e no encaminhamento para o especialista. RevistaPaulista de Pediatria. 2002;20:280-2.

7. SA Thierry S, Fautrel B, Lemelle I, Guillemin F. Prevalence and incidence of juvenile idiopathic arthritis: a systematic review. Joint Bone Spine. 2014;81:112-7.

8. Kumar S. Need for determining the incidence and prevalence of JIA in developing countries: the Indian predicament. Rheumatology (Oxford) 2010;49(8):1598-9.

9. Kuhlmann A, Schmidt T, Treskova M, López-Bastida J, Linertová R, OlivaMoreno J, et al. BURQOL-RD research Network.Social/economic costs and health-related quality of life in patients with juvenile idiopathic arthritis in Europe. Eur J Health Econ. 2016;17(Suppl 1):79-87.

10. Steven MM. Prevalence of chronic arthritis in four geographical areas of the Scottish highlands. AnnRheumDis. 1992;51 (2):186-94.

11. Mielants $\mathrm{H}$, Veys EM, Maertens M, Goemaere S, De Clercq L, Castro S, et al. Prevalence of inflammatory rheumatic diseases in an adolescent urban student population, age 12 to 18, in Belgium. ClinExpRheumatol. 1993;11 (5):563-7.

12. Manners PJ, Diepeveen DA. Prevalence of juvenile chronic arthritis in a population of 12-year-old children in urban Australia. Pediatrics. 1996;98(1): 84-90.

13. Tayel MY, Tayel KY. Prevalence of juvenile chronic arthritis in school children aged 10 to 15 years in Alexandria. J Egypt Public Health Assoc. 1999;74(5-6); 529-46.

14. Mauldin J, Cameron HD, Jeanotte D, Solomon G, Jarvis JN. Chronic arthritis in children and adolescents in two Indian health service user populations. BMC Musculoskelet Disord. 2004:5:30.

15. Azam S, Dipti T, Rahman S. Prevalence and clinical pattern of juvenile idiopathic arthritis in a semi-urban area of Bangladesh. Int J Rheum Dis. 2012;15(1):116-20

16. Yamashita E, Terreri MTRA, Hilário MOE, Len CA. Prevalência da artrite idiopática juvenil em crianças com idades entre 6 e 12 anos na cidade de Embu das Artes, SP. Rev BrasReumatol. 2013;53(6):542-5.

17. Abujam B, Mishra R, Aggarwal A. Prevalence of musculoskeletal complaints and juvenile idiopathic arthritis in children from a developing country: a school-based study. Int J Rheum Dis. 2014;17(3):256-60.

18. Abdwani R, Abdalla E, Al Abrawi S, Al-Zakwani I. Epidemiology of juvenile idiopathic arthritis in Oman. PediatrRheumatol Online J. 2015;13:33.

19. Organização Pan-Americana da Saúde, Fundação Nacional de Saúde, Centro Nacional de Epidemiologia.Módulo1: estudos de prevalência. Método de investigação epidemiológica em doenças transmissíveis. [Internet] Goiás. Universidade Federal de Goiás. [Acesso 10 nov 2017]. Disponível em https:// posstrictosensu.iptsp.ufg.br/n/4845-material-de-epidemiologia.

20. Len CA, Terreri MT, Puccini RF, Wechsler R, Silva EK, Oliveira LM, et al. Development of a tool for early referral of children and adolescents with signs and symptoms suggestive of chronic arthropathy to pediatric rheumatology centers. Arthritis Rheum. 2006;55(3):373-7.

21. Scheer T, Klotsche J, Len C, Foeldvari I. Validating and developing a selectec questionnaire to predict early diagnosis of juvenile idiopathic arthritis in german population. Pediatr Rheumatol. 2018;16(Suppl 2):P091.

22. Secretaria da Educação - Governo do Estado de São Paulo [homepage na internet] Censo escolar - Estado de São Paulo - Informe 2014[Acesso 10 nov 2017]. Disponívelem https://www.educacao.sp.gov.br/censo-escolar.

23. Fleiss JL, Levin B, Paik MC. Statistical methods for rates and proportions. Third edition. John Wiley \& Sons. New York. Newcombe, R. G. 1998. 'Twosided confidence intervals for the single proportion: comparison of seven methods. Stat Med. 2003;17:857-72.

24. Instituto Brasileiro de Geografia e Estatística [homepage na internet] Censo demográfico 2010: sinopse. [Acesso 10 nov 2017]. Disponível em https:// cidades.ibge.gov.br/xtras/temas.php?lang=\&codmun=355030\&idtema= $1 \&$ search=sao-paulo|sao-paulo|censo-demografico-2010:-sinopse.

25. Markoni MA, Lakatos EM. Fundamentos de metodologia científica. 6a ed. São Paulo: Atlas; 2005.

26. Vieira HC, Castro AE, Júnior Schuch VF. O uso de questionários via e-mail em pesquisas acadêmicas sob a ótica dos respondentes. XIII SEMEAD Seminários em administração. 2010. Disponível em: http://sistema.semead. com.br/13semead/resultado/an_resumo.asp?cod_trabalho=612.

\section{Publisher's Note}

Springer Nature remains neutral with regard to jurisdictional claims in published maps and institutional affiliations.

\section{Ready to submit your research? Choose BMC and benefit from:}

- fast, convenient online submission

- thorough peer review by experienced researchers in your field

- rapid publication on acceptance

- support for research data, including large and complex data types

- gold Open Access which fosters wider collaboration and increased citations

- maximum visibility for your research: over $100 \mathrm{M}$ website views per year

At $\mathrm{BMC}$, research is always in progress.

Learn more biomedcentral.com/submissions 